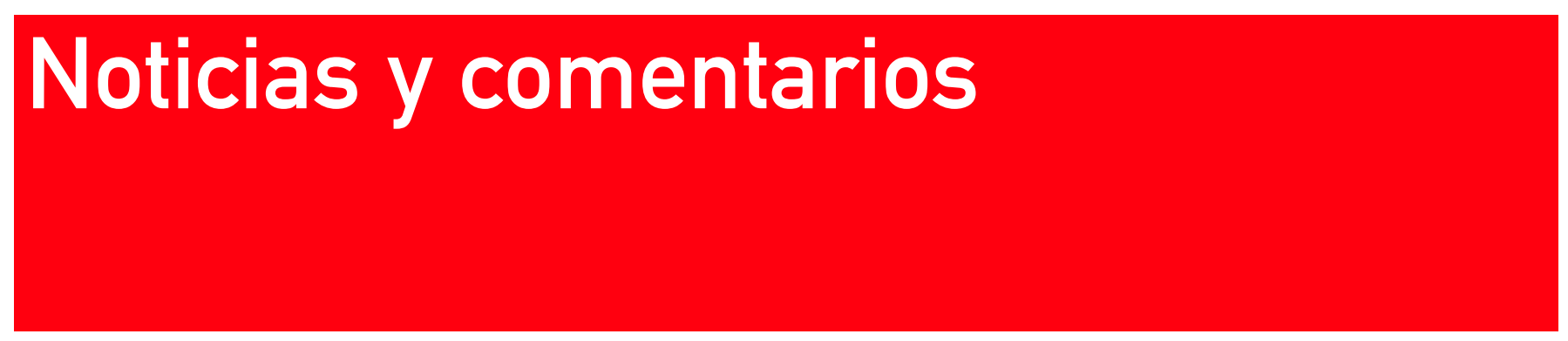

\title{
Compromiso en clave de cultura, poder y mercado
}

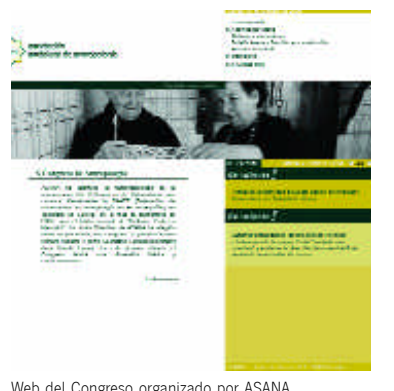

Web del Congreso organizado por ASANA

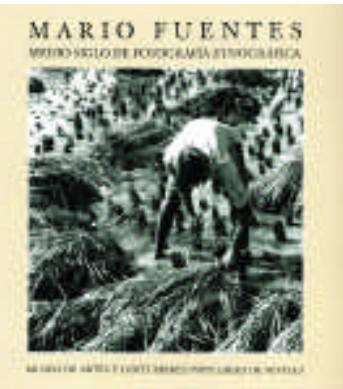

Catálogo fotográfico de la exposición "Mario Fuentes: medio siglo de Fotografia etnográfica"
El X Congreso de Antropología de la Federación de Asociaciones de Antropología del Estado Español (FAAEE) se celebró del 19 al 22 de septiembre de 2005 en Sevilla, organizado por la Asociación Andaluza de Antropología (ASANA). Con el encuentro, que giraba en torno al lema "Cultura, poder y mercado", se pretendia responder a la intencionalidad, acorde con la filosofía recogida en congresos anteriores, de convertir este encuentro en un foro de debate abierto, donde la diversidad de simposios (12), grupos de trabajo (4), ponencias y comunicaciones (212), reflejaran la compleja y contradictoria realidad de las sociedades en que vivimos. Sus organizadores querían con todo ello reflejar la necesidad de la mirada antropológica, rigurosa pero no des comprometida, y la validez de su aporte teóricometodológico para analizar las claves políticas, sociales, económicas y simbólicas del mundo en el que nos encontramos.

Con esta intención de partida se pusieron en relación los términos de cultura, poder y mercado. Si las culturas, en su diversidad de contenidos y matices, constituyen el principal activo patrimonial de los colectivos humanos, no podemos dejar de concebirlas sin algo consustancial al propio hecho cultural: los discursos que desde el poder se hacen sobre ellas. Actualmente estos discursos han adquirido unas significaciones sociopolíticas muy relevantes en relación con las identidades, los nacionalismos, las sociedades pluriétnicas y los discursos patrimonialistas. Al mismo tiempo, estos discursos y acciones políticas están relacionados con las lógicas mercantilistas como factor determinante de la globalización actual, promoviéndose, a través de bienes culturales transformados en productos, un verdadero consumo de identidades/tradiciones, acorde con las concepciones de ocio-turismo como alternativa de la crisis de otros sectores económicos. Se llama la atención sobre el hecho de que en este contexto la diversidad cultural corre el peligro que supone el avance de la homogeneización, pretendidamente universalista, que presenta como inevitable la implantación de una única lógica cultural para todos los pueblos, siendo sólo respetadas las diferencias y especificidades en tanto signifiquen beneficios en los mercados.

Desde este marco, entendido como el más idóneo, se partió para contextualizar la multitud de temas y problemas que son hoy tratados desde la antropología, y que se plasmaron en los diferentes simposios, conferencias y mesas de trabajos a través de numerosas intervenciones (los simposios "Patrimonio cultural: politizaciones y mercantilizaciones" y "El encuentro del turismo con el patrimonio cultural: concepciones teóricas y modelos de aplicación" son tratados a continuación de forma especifica por sus respectivos coordinadores).

Al cierre del Congreso, el balance era muy positivo con una participación, más que numerosa, de 400 congresistas reunidos en torno a doce simposios, 212 comunicaciones y cuatro mesas de trabajo. Además se consiguió el objetivo de otorgarle a este congreso un carácter internacional, gracias a la participación activa de antropólogos/as del conjunto de los Pueblos Ibéricos, incluido Portugal, y otros ámbitos territoriales, preferentemente del mundo latinoamericano.

Por otro lado la Organización del Congreso cumplió con el objetivo de publicar antes del inicio del Congreso y poner a disposición de los participantes varias publicaciones: los doce tomos correspondientes a los textos de los simposios y un tomo específico dedicado a las conferencias plenarias.

Además de los textos de las comunicaciones y conferencias, los organizadores del X Congreso realizaron dos homenajes muy merecidos en el ámbito de la antropología andaluza: la publicación de la obra póstuma de José Alcina Franch, Justicia y Libertad. La larga marcha hacia un futuro incierto, quien fue realmente, en palabras de Isidoro Moreno, el "padre" de la Antropología Andaluza, y éste su libro el "de mayor madurez y radicalidad y su aportación más totalizadora como antropólogo, como pedagogo y como intelectual"; el segundo acto de homenaje realizado por el congreso, y que también se ha plasmado en la publicación de un catálogo fotográfico, fue la exposición "Mario Fuentes: medio siglo de Fotografía etnográfica" en el Museo de Artes y Costumbres Populares, donde se reflejaba parte del trabajo fotográfico de su autor y, a través de él, medio siglo de memoria colectiva andaluza y de los cambios ocurridos en una amplia diversidad de manifestaciones de la vida cotidiana de algu- 


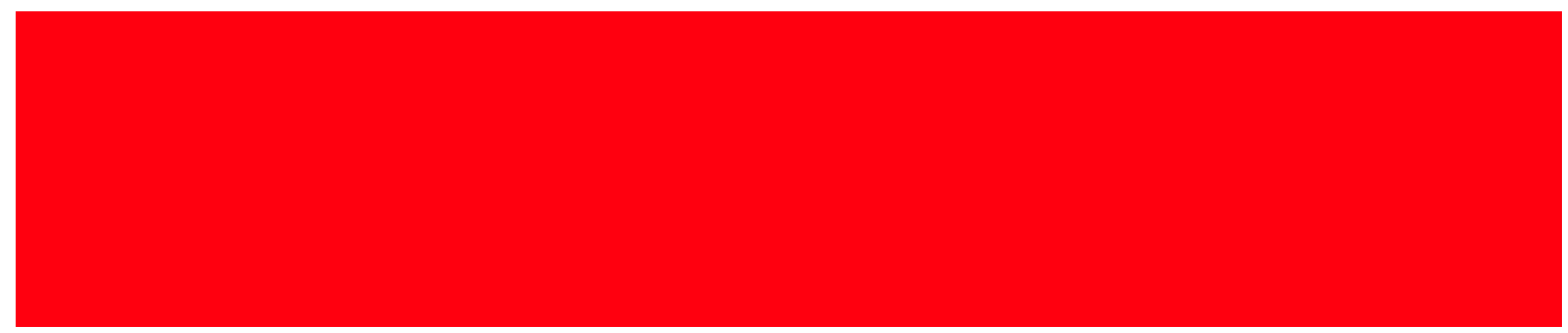

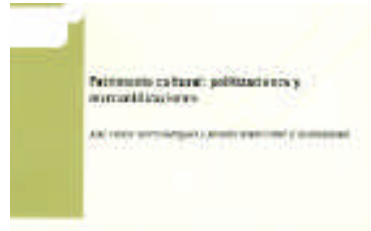

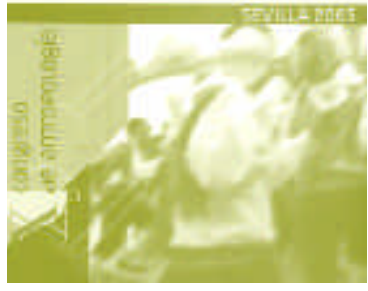

Portada de una de las actas publicadas
${ }^{1}$ PEIXOTO, P. (1998) "Os meios rurais e a descoberta do património", en

www.ces.fe.uc.pt/publicacoes/oficina/175 /175.php nos pueblos de Andalucía, plasmados en imagen fotográfica a partir de una mirada antropológica.

Para todo ello, el comité organizador contó con la ayuda y el trabajo de un importante número de voluntarios y con la colaboración y aportación económica de diferentes entes públicos y privados, sin los cuales hubiera sido imposible el desarrollo de este Congreso.

Gema Carrera Diaz

Antropóloga

Centro de Documentación del IAPH fesionales de la antropología con trabajo de campo en España, Portugal, México, Estados Unidos y República Dominicana. Durante el mismo se presentaron casos de estudio pero también se realizó una reflexión teórica sobre la relación entre el patri monio cultural y los procesos de mercantilización y politización del mismo.

El simposio sirvió para crear un espacio de debate entre antropólogos especialistas en patrimonio cut tural. Dos fueron las perspectivas desde las que se reflexionó: a) desde la intervención y activación del patrimonio cultural; b) desde la reflexión crítica y relativista sobre los procesos de patrimonialización. Entre las dos se generó un consenso sobre la necesidad de lecturas sociales y antropológicas de la construcción del patrimonio cultural, de cara a su rentabilidad social.

Simposio sobre patrimonio cultural: politizaciones y mercantilizaciones

Xerardo Pereiro Pérez. Universidade de Trás-os-Montes e Alto Douro (UTAD)

Xosé Carlos Sierra Rodríguez. Museo Etnológico de Ribadavia-Ourense

La histeria patrimonial' (Peixoto, 1998) que vivimos desde hace tiempo no puede ser entendida sólo como una bienintencionada conservación de memorias y simbólicas de la cultura. Pensamos que es importante analizar transculturalmente los procesos de mercantilización y politización del patrimonio cultural, para mejor entender los procesos de patrimonialización de la cultura. ¿Hasta qué punto estos procesos de valorización de la herencia cultural deberían de ser vistos y entendidos desde las políticas de excepción cultural? ¿Cuáles son los riesgos de la mercantilización excesiva? ¿Será que la politización exagerada del patrimonio cultural reduce la pluralidad de identidades a unas pocas versiones de esas identidades múltiples? ¿Cómo el profesional de la antropología puede entender, comprender e intervenir en estos procesos dialécticos? ¿Cómo el patrimonio cultural y su activación puede contribuir al desarrollo de modelos político-sociales más justos y solidarios?

Estas fueron algunas de las cuestiones clave que fueron tratadas en el simposio "Patrimonio Cultural: Politizaciones y Mercantilizaciones", enmarcado en el congreso de la FAAEE. El simposio contó con 10 magníficas contribuciones de pro-
A lo largo del simposio se pudo constatar cómo el patrimonio cultural ha sido incorporado ferozmente al Mercado en las últimas décadas y parte de sus lógicas no pueden entenderse sin éste, pero también sin la importancia que ha pasado a tener para la Política y sus afirmaciones. En las actas del simposio se pueden estudiar los usos sociales, mercantiles y políticos del patrimonio cultural, que ha sido perspectivado de la siguiente forma:

$>$ Como un proceso de lucha por el espacio, los recursos y la definición de las identidades. En este proceso pueden producirse dominaciones, resistencias y contestaciones.

$>$ Como una etiqueta de distinción de diferentes territorios utilizada por la mercadotecnia cultural. $>$ Como un espacio de relaciones entre lo local y lo global. sobre la ruralidad y la urbanidad, idealizando así continuidades y rupturas.

> Como una vía y estrategia no única ni suficiente para el desarrollo.

$>$ Como algo que se fabrica socialmente y a lo cual también contribuyen los antropólogos, en cuanto especialistas y agentes de la patrimonialización.

$>$ Como algo que obedece a lógicas identitarias, políticas y mercantiles que pueden chocar entre si. $>$ Como una industria de objetivación de la cultura y de creación de audiencias (consumos).

$>$ Como un ejercicio de visibilización e invisibilización de memorias e identidades.
$>$ Como fuente de nuevas imágenes y discursos 


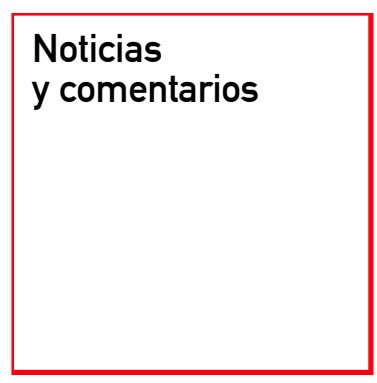

Durante los debates, los participantes defendieron la necesidad de reconocer al antropólogo como un profesional técnico del patrimonio cultural, con capacidad para investigar, interpretar e intervenir con sus conocimientos, teorías, éticas y métodos en la construcción social de un patrimonio cultural más democrático. Del mismo modo también se propuso la idea de crear un foro permanente dentro de la FAAEE para dar cabida a un mayor intercambio de ideas.

Simposio sobre el encuentro del turismo con el patrimonio cultural: concepciones teóricas y modelos de aplicación

Llorenç Prats. Dpto. de Antropologia.

Universitat de Barcelona

El patrimonio cultural constituye un elemento clave para el presente y el futuro de nuestra sociedad, tanto por su vinculación con el turismo como por su virtualidad simbólica en el juego de la continua redefinición y reformulación de viejas y nuevas identida des en un contexto globalizado. Más allá de la cons trucción romántica de identidades nacionales, acordes con los intereses y discursos hegemónicos, más allá de la apropiación y estereotipos (que Andalucía conoce especialmente), así como de la burda explotación de referentes patrimoniales como recursos turísticos, el patrimonio cultural se presenta como una herencia colectiva inenajenable y plural en sus construcciones y significaciones. Con toda la riqueza semántica que contiene la frase de José Luis García, el patrimonio constituye "recursos para vivir".

El papel estratégico del patrimonio se acentúa en nuestro caso si aceptamos que el posicionamiento económico de España dentro de la Unión Europea (y del mercado global) va a consistir básicamente en la prestación de servicios turísticos (y geriátri cos), a lo cual se debe añadir la preocupación existente (especialmente en la administración, según mis impresiones) por superar, mejorar o recalificar el modelo predominante de turismo de sol y playa del que hemos venido viviendo hasta ahora, y la fijación en el patrimonio (natural y cultural, es lo mismo), si no como panacea, sí como principal activo para esa reconversión.

Por otra parte, pero también dentro de un plano utilitarista, la nueva situación académica que va a definir el proceso de convergencia universitaria europea va a situar, en el mejor de los casos, al patrimonio etnológico, como parte del patrimonio cultural, como objetivo clave de la dedicación profesional de los futuros antropólogos y antropólogas. De hecho, de las capacitaciones profesionales previstas en el borrador de libro blanco elaborado para el grado de Antropología ésta es tal vez la más inequívoca ¿Quién si no los antropólogos va a interpretar esa vastísima y compleja herencia popular que vendría a ser el patrimonio etnológico?
Frente a esa situación de facto, la respuesta académica y profesional es más bien caótica. El patrimonio, y no digamos el turismo, ocupa un ámbito marginal dentro de nuestros actuales planes de estudio, de las líneas preferentes de inves tigación de la mayoría de los grandes departamentos y de los intereses personales de los profesionales académicos consolidados. Véanse planes de estudios, proyectos de investigación y publicaciones. La dedicación al patrimonio es vista con frecuencia, sin más, como un retoque cosmético de antiguos e inconfesables intereses folklóricos y el estudio del turismo desde la antropología como una frivolidad, sólo justificable en todo caso en aquellas universidades ubicadas en zonas que han vivido el supuesto trauma acultur rador del turismo de masas. Estas percepciones son erróneas, injustas y peligrosas para el futuro de la antropología, pero explicables.

Por una parte, el turismo es un negocio que ha marchado viento en popa y el sector, en consecuencia, no ha tenido excesivo interés en fomen tar complejos estudios al respecto (y por ende tampoco las administraciones). Cuando algo funciona más vale no removerlo. En todo caso, los estudios se han centrado fundamentalmente en conocer los niveles de satisfacción, los factores mejorables para un mayor rendimiento y los impactos más críticos sobre el territorio y la población. Poca cosa han podido hacer los antropólogos al respecto más que añadirse inicialmente a las críticas desde un punto de vista más especificamente cultural, o, superada esta fase infantil, podríamos decir, de la antropología del turismo, clamar casi en el desierto por la elaboración de modelos más complejos y menos maniqueos para dar cuenta de una realidad asimismo extremadamente compleja y diversa.

El patrimonio, especialmente la activación y ges tión de patrimonios locales, ha sido la tabla de salvación profesional de no pocos antropólogos y antropólogas que no tenían lugar en la academia. Estas activaciones más o menos locales han nacido generalmente de intereses políticos concretos, en la medida en que el patrimonio tiene una gran rentabilidad electoral, y también de una ecuación perversa que se ha dado acríticamente como uni versalmente válida, que propugna que la activación patrimonial atrae turismo, que va a procurar en mayor o menor grado el desarrollo de la zona en cuestión. Esto es así sólo en algunos casos y en cierta medida, normalmente en relación con referentes patrimoniales muy potentes (que no abundan) o en el contexto de zonas turísticas previamente desarrolladas. En el resto de los casos suele producir los efectos políticos deseados a corto plazo pero no el flujo turístico y el desarrollo prometido como nuevo maná del consumismo lúdico. Sin embargo, los gestores de estas activaciones patrimoniales, o turistico-patrimoniales, supuestamente, en buena lógica no van a denun- 
ciar el fracaso de un proyecto del cual depende su sustento, sino que intentarán defenderlo con uñas y dientes, forzando en ocasiones su imaginación hasta límites dignos de mejores empresas.

El desinterés académico, unido a una supuesta bondad y eficacia de la reconversión turístico patrimonial en abstracto y el atrincheramiento de multitud de pequeñas iniciativas atomizadas, dan cuenta de la pobreza y marginalidad de la reflexión teórica y metodológica respecto al patrimonio, el turismo y, como decíamos en el simposio, sus confusas relaciones. Una pobreza que no es exclusiva de España pero que, atendiendo al carácter genéricamente periférico de nuestra contribución global al conocimiento científico, presenta aquí sintomas más agudos que en otros países y contextos académicos (y menos que en otros).

Por eso se convocó el simposio "El encuentro del turismo con el patrimonio cultural: concepciones teóricas y modelos de aplicación" dentro del X Congreso de Antropología, y por eso, su conclusión no podía ser otra que la imperiosa necesidad de dedicar más recursos y esfuerzos académicos y profesionales a la investigación en estos campos y en su intersección, con la tarea primordial de deshacer entuertos, es decir, desmentir falsas certidumbres, y elaborar modelos afinados y complejos para analizar una tan rica y crucial realidad. Algo se ha hecho, pero es mucho más lo que queda aún por hacer.

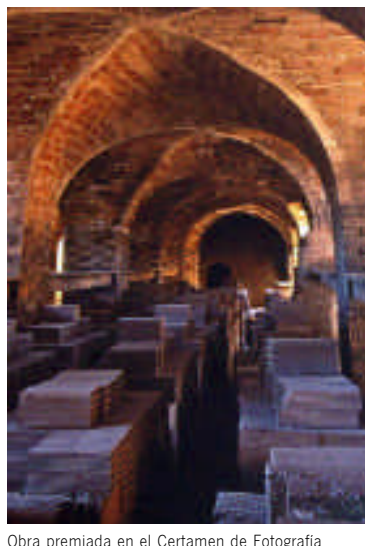

Obra premiada en el Certamen de Fotografii

\section{INCUNA rastrea en Gijón las huellas de Atenea}

La asociación INCUNA Máximo Fuertes Acevedo organizó por séptimo año consecutivo las Jornadas Internacionales de Patrimonio Industrial, desarrolladas en Gijón del 21 al 24 del pasado septiembre. El tema central de las jornadas giró en torno a "Las huellas de Atenea: el patrimonio industrial de la guerra en tiempos de paz". Se presentaron medio centenar de comunicaciones, de ámbito tanto nacional como internacional, relacionadas con el estudio, el análisis, la interpretación y la puesta en valor del amplio patrimonio histórico e industrial relacionado con la guerra y con la política de defensa de los paises, con especial atención a España desde finales del siglo XVIII.

Entre los aspectos abordados destacaron los medios de transporte construidos por y para la guerra; las obras de ingeniería civil; las fuentes documentales y la documentación para el estudio del patrimonio industrial de guerra; la recuperación de modelos de tropa, indumentaria y armamento originales; los equipos de control y represión, y la fabricación de armas y armamento, en general. Para ilustrar este último aspecto se realizó un itinerario por las fábricas de La Vega (Oviedo) y Trubia, que proceden de finales del siglo XVIII y aún están en funcionamiento.

Coincidiendo con las jornadas, la ciudad asturiana acogió el seminario TICCIH -Comité Internacional para la Salvaguarda del Patrimonio Industrial"Patrimonio Industrial. Lugares en peligro", al que asistieron -por primera vez en la historia de la asociación- representantes de todas las Comunidades Autónomas españolas. De esta forma, se elaboró un documento exhaustivo sobre el estado del patrimonio industrial en todo el pais, en el que se alerta sobre el peligro inminente que se cierne sobre algunas instalaciones. El documento íntegro estará disponible en el futuro en la página web de $\mathrm{TIICIH}$ España (www.mnactec.com/ticcih/).
Sobre la base de ese informe, TICCIH-España pretende dirigirse a las administraciones públicas, las empresas y los ciudadanos en general para llamar la atención sobre el valor de los lugares señalados, que representan "muestras dignas de preservación de la memoria industrial y cultural, ya que constituyen conjuntos productivos sin los cuales sería imposible entender la evolución de la historia humana reciente".

\section{Casi 150 asistentes}

Casi 150 asistentes participaron en las jornadas, incluido un 10 por ciento de estudiantes de la Universidad de Oviedo. Ante ellos desgranaron sus intervenciones los ponentes invitados por INCUNA, empezando por un representante de la Subdirección General de Acción Cultural y Patrimonio Histórico del Ministerio de Defensa, que detalló el riquísimo patrimonio del Ejército, tanto por el valor de sus edificios históricos como por lo que muchos de ellos contienen. Tal como sostiene el coronel Aurelio Manuel Valdés Sánchez -responsable del departamento-, "la riqueza del patrimonio ubicado en instalaciones del Ministerio de Defensa es sólo comparable por extensión con el de la Iglesia".

Los asistentes escucharon con especial atención las intervenciones internacionales, entre las que abrió el fuego Jeremy Lake, inspector de monumentos del English Heritage, que explicó particularidades del sistema de Defensa utilizado por el Alto Mando Británico durante la Segunda Guerra Mundial. De ese periodo proceden también las instalaciones objeto de la intervención de Noël Guetny y Sophie Minssart, responsables de la reconversión para uso público de la base submarina construida por el régimen nazi en la localidad francesa de Saint-Nazaire.

De mucho antes data el origen de la Fundición West Point, que tuvo un destacadísimo papel en el desarrollo, la fabricación y el suministro de arma- 